\title{
Effects of Diesel-Biodiesel Blends in Diesel Engine Single Cylinder on the Emission Characteristic
}

\author{
Erdiwansyah $^{1,2}$, R. Mamat ${ }^{1}$, M.S.M. Sani ${ }^{1}$, Fitri Khoerunnisa ${ }^{3}$, R.E Sardjono ${ }^{3}$, OM Ali ${ }^{4}$, TK \\ Ibrahim $^{5}$, \\ ${ }^{1}$ Faculty of Mechanical Engineering, Universiti Malaysia Pahang, Pekan, Pahang 26600 Malaysia \\ ${ }^{2}$ Fakultas Teknik, Universitas Serambi Mekah Aceh 23249, Indonesia \\ ${ }^{3}$ Department of Chemistry, Universitas Pendidikan Indonesia \\ ${ }^{4}$ Northern Technical University, Iraq \\ ${ }^{5}$ Tikrit University, Iraq
}

\begin{abstract}
Biodiesel is an alternative fuel that is used in a diesel engine as a substitute for diesel fuel. However, using biodiesel without a modified engine can cause higher NOx emissions. Therefore, to reduce harmful emissions some strategy must be proposed or or a change in the injection is performed. In this study, injection schemes and engine performance injection time, emissions and firing characteristics of biodiesel mixing results in engines were investigated by using GT-POWER simulation. The simulations in this study were conducted on diesel engines to observe the accuracy in experimental results . The engines were tested at speeds of 1100 rpm, $1300 \mathrm{rpm}$, and $1500 \mathrm{rpm}$ by using a biodiesel-diesel fuel mixture. The simulation results showed that NOx emissions were found to drop below 100 ppm when biodiesel fuel was used for all performed operations. Meanwhile $\mathrm{CO}$ emissions were also decreased by $10 \%-15 \%$ when biodiesel fuel was used, and the thermal efficiency level increased by $2 \%$ and $3.5 \%$ as compared to pure diesel. The ratio of NOx reduction rates of biodiesel and diesel was $11 \%-14 \%$ as compared to $9.5 \%$ with pure diesel. Based on the simulation result, it was shown that the accuracy level of simulation data with experiment was $97 \%$. So this result can be the future testing standard and simulation by using GT-POWER could also be used especially for the automotive industry.
\end{abstract}

\section{Introduction}

Today the increasing demand for fossil fuels is due to the growing industry, both large and medium-sized, among the public. Increased pollutant emissions caused by petroleum-fuelled fuels and the increasingly detrimental environmental impacts have led many research to investigate alternative fuels instead of fossils derived from a variety of plant and waste materials abundantly found in the country [1]-[3].

Biodiesel fuel is one of the biofuels that can be used to replace fossils because biodiesel has very superior combustion characteristics that have similarities to mineral diesel. The 
biodiesel capability for combustion engines has been illustrated by some literature that has an effect and is directly related to performance and emissions on the machine [4]-[7]. Biodiesel has several advantages, such as higher oxygen content, high cetane numbers, and lower sulphur [8]-[10]. Therefore, some research on the emission combustion characteristics were investigated by describing different results from the use of blended biodiesel fuel into diesel [11], [12]. Properties contained in internal combustion engines are strongly influenced by some parameters related to fuel-air, turbulence, vortex flow, and EGR speed. The change in the machine input power is strongly influenced by combustion properties, such as heat release rate, pressure inside the cylinder, and temperature. This result has been demonstrated by several experiments which suggested that cyclic dispersions and variations in combustion engines and combustion velocities will occur when combustion begins [13]-[17]. Some literature explained that many factors can influence the dispersion in combustion fraction in the engine. However, the relative factors cannot be fully determined yet, such as dependence on the design and operating variables in the combustion engine. Therefore, it is important to research a variety of emissions in internal combustion engines to understand machine behaviour by using new technology when using alternative fuels. Measuring and analysing emissions by experimenting or simulating for internal combustion engines as very well documented by researchers all over the world [11], [18]-[20]. Currently, many researchers have investigated on the machine by conducting experiments with alternative fuels to reduce combustion emissions. Recent research conducted on diesel engines by using standard fuels, such as biodiesel [11], [13], [21]. Observations made showed that the use of biodiesel can improve fuel efficiency as compared to pure diesel [8].

In addition to experimental research, some researchers also have researched engine emissions in by using alternative fuel through simulations, such as GT-POWER. The simulation with GT-POWER is finished to observe and compare the simulation results with the experiments, whereby some completed simulations stated that GT-POWER software has data accuracy of up to $95 \%$ more [22]. The research by Rahim et al. [23] simulations was performed to observe emissions by using ethanol fuel. The simulation results from the generated data can resemble experimental results of up to $97 \%$. Different studies by using GT-POWER have also been performed by [24]. The simulation results can be trusted with the experimental results because all parameters contained on the engine were adjusted with the parameters on the GTPOWER.

This study aims to investigate the characteristics of emissions on internal combustion engines fuelled by biodiesel-diesel fuel (B20D80 and diesel) through a simulation by using the GTPOWER software. Testing is completed with engine speed at 1,100 rpm, 1,300 rpm, and $1,500 \mathrm{rpm}$. The simulation results were analysed and compared with the experimental results.

\section{Material and method}

In this study, simulations were made by adjusting the parameters contained in diesel engines and the biodiesel-diesel fuel adapted at the time of experimentation in the machine. This simulation was finished with three different engine speeds between 1,100 rpm, 1,300 rpm, and 1,500 rpm. The fuel mixture was tested with the ASTM standard to adjust the properties of each biodiesel-diesel intended for flash point, pour point, and viscosity. The fuel properties used for the test were usually made each time the experiment was performed, as shown in Table 1. The modelling simulation for the development of a single-cylinder direct injection (DI) engine diesel with GT-Power and engine test Yanmar TF120-M, is as shown in Fig. 1. The maximum speed of this machine was $2,400 \mathrm{rpm}$ for $7.8 \mathrm{~kW}$. The specifications of the single cylinder diesel engines and parameters were entered into the GT-POWER as observed in Table 2. 
Table 1. Specifications test fuel properties [25]-[27]

\begin{tabular}{|l|l|l|}
\hline Description & \multicolumn{1}{|c|}{ Diesel } & Biodiesel \\
\hline Cetane number & 46 & 48 \\
\hline Density $(\mathrm{kg} / \mathrm{m} 3)$ & 835.0 & 883 \\
\hline Flash Point $\left({ }^{\circ} \mathrm{C}\right)$ & 71.5 & 140 \\
\hline Heating Value $(\mathrm{MJ} / \mathrm{kg})$ & 45.72 & 40.420 \\
\hline Kinematic viscosity at $40^{\circ} \mathrm{C}$ & 2.985 & 4.15 \\
\hline
\end{tabular}

Table 2. Specifications diesel engine single cylinder (Yanmar Model TF120M) [28]

\begin{tabular}{|l|l|l|l|}
\hline Compression ratio & $17.7: 1$ & Max rating output & $12.0 \mathrm{HP} @$ @ 2400 rpm \\
\hline Continuous rating output & $10.5 \mathrm{HP} @ 2400 \mathrm{rpm}$ & Type & 1 -cylinder 4-stroke \\
\hline Fuel tank capacity & $11 \mathrm{~L}$ & Max power & $7.7 \mathrm{~kW} @$, 2400 rpm \\
\hline Displace volume $\left(\mathrm{cm}^{3}\right)$ & 638 & Max torque & $161 \mathrm{Nm} @$, 4500 rpm \\
\hline Fuel injection type & Direct Injection & Cooling system & Water-radiation \\
\hline Bore $(\mathrm{mm})$ & 92 & Stroke $(\mathrm{mm})$ & 96 \\
\hline
\end{tabular}

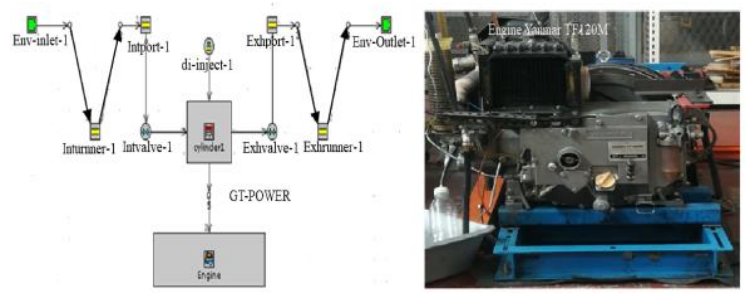

Fig. 1. GT-Power and Engine Yanmar TF120M

\section{Result and discussion}

The effect of biodiesel fuel mixtures was added to the diesel on emissions and diesel engine performance was discussed and analysed in this simulation study. The experiments in the simulation were finished by using 1,100 rpm, 1,300 rpm, and 1,500 rpm engine speeds to generate and verify the exhaust emissions data in the engine. Furthermore, the simulation results were analysed based on experimental results.

\subsection{Exhaust gas temperature.}

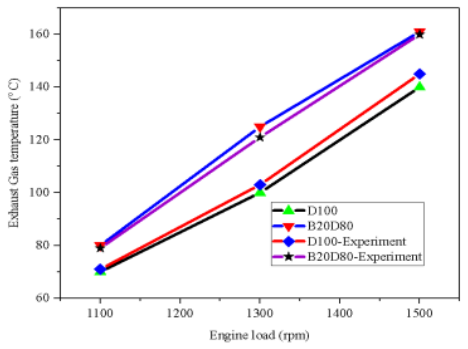

Fig. 2. Comparison of exhaust gas temperature in engine load for simulation and experiment.

The exhaust gas temperature variation from the test results by using fuel and brake power is as shown in Figure 2. Increased exhaust gas temperature and engine load was due to a greater fuel power supplied. The increasing mode of exhaust gas temperature from the use of 
biodiesel-diesel fuel fuels can reduce the biodiesel trend, better known as B20, as an additive as compared to the use of pure diesel fuel. Biodiesel fuel will usually burn late during the combustion phase due to very poor volatility. The addition of biodiesel to the pure diesel can make the guide to complete the fuel burn on the engine because increase in cetane numbers can shorten the engine burning delay period

\subsection{Thermal efficiency}

Biodiesel fuel demonstrates higher efficiency which is an additive as compared to pure diesel fuel, as shown in Figure 3. The energy content contained in biodiesel fuel is lower than that of pure diesel by $5 \%-10 \%$. When biodiesel fuel is mixed into diesel, the energy content of the fuel changes. The low energy content derived from mixing biodiesel fuel can reflect the engine performance slightly reduced as compared to pure diesel. Increased oxygen content due to cetane number, lower fuel viscosity, and lower density can directly complete combustion in the engine. Similar results were also presented by several researchers, as found in literature [21], [4], [28].

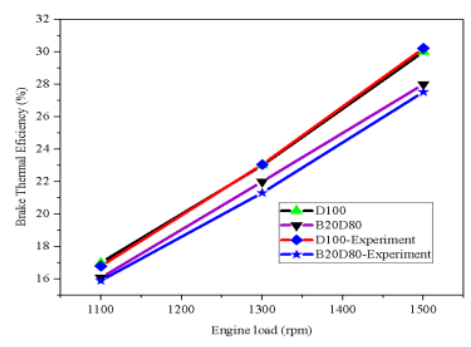

Fig. 3. Comparison of brake thermal efficiency in engine load for simulation and experiment.

\subsection{Carbon monoxide emission}

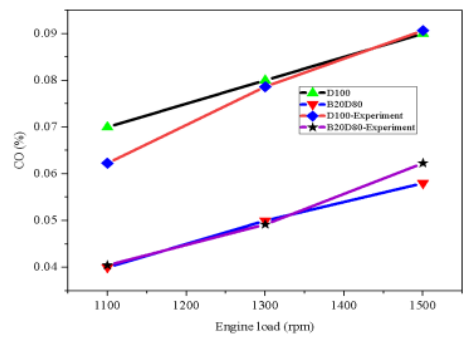

Fig. 4. Comparison of carbon monoxide emissions in engine load for simulation and experiment.

The percentage of variations in carbon monoxide emissions with engine loads when testing the use of diesel-fuel biodiesel is as shown in Figure 4. The mixture of air-rich biodieseldiesel fuel can produce $\mathrm{CO}$ because of the unavailable oxygen that can promote $\mathrm{CO}$ concentration for fuel [29], [30]. The lower emissions from the use of biodiesel-diesel fuel rather than pure diesel for the entire load spectrum of the engine due to the oxygen present in biodiesel, so that fuel use can support full combustion in the cylinder chamber. On the other hand, mixed fuels from biodiesel can reduce $\mathrm{CO}$ emissions by $10 \%-15 \%$. The reduction in $\mathrm{CO}$ is caused by oxygen which is increased more in biodiesel-diesel fuel mixture. More complete combustion can be caused by increased chemistry in mixed fuel. 


\subsection{NOx emission}

Based on biodiesel-diesel fuel mixtures, it can be reported that NOx emissions had increased by $9.5 \%$ as compared to using pure diesel. However, the positive response indicated by biodiesel fuel at the time of mixing NOx can be reduced by $11 \%$ to $14 \%$. This increase is very reasonable because the fuel cetane number can provide the ignition speed at the start of combustion. So, the ignition delay has caused it to decrease with the shortened time in the initial combustion phase. NOx emissions were found to decrease as the generated burning temperature also decreased. The reduced exhaust gas temperature can be clearly observed in Figure 2. The results of research on NOx emissions have been widely researched and reported in literature, where the use of biodiesel mixed fuels can significantly reduce NOx [11], [31], [32].

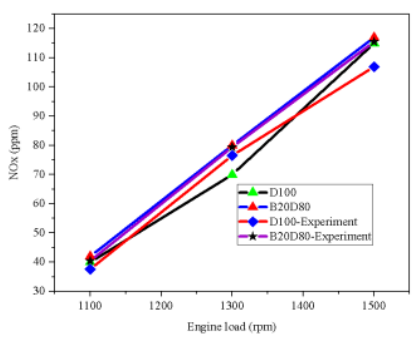

Fig. 5. Comparison of NOx emissions in engine load for simulation and experiment

\section{Conclusion}

In this study, the exhaust gas characteristics of mixed biodiesel and diesel fuels were tested by using a GT-POWER simulation by adjusting the results data from the experiments. Simulations by using engine speeds of $1,100 \mathrm{rpm}, 1,300 \mathrm{rpm}$, and $1,500 \mathrm{rpm}$ at constant machine loads, investigations of exhaust emissions have been widely implemented in literature by some researchers. The main conclusions of this simulation are carried out as described below:

- The decrease was also found in the exhaust gas temperature and NOx with a few penalties.

- $\quad$ The use of biodiesel fuel mixed into diesel can significantly reduce $\mathrm{CO}$ emissions by $10 \%-15 \%$.

- $\quad$ The biodiesel-diesel fuel blend can increase NOx emissions by $9.5 \%$ as compared to pure diesel. However, the positive response showed by biodiesel fuel can reduce NOx emissions by $11 \%$ to $14 \%$.

- $\quad$ The lower energy content can reduce engine performance. However, a biodieseldiesel mixture can improve brake heat efficiency.

- The simulation in this study was used to observe the accuracy of the data from experiments, where the exhaust emissions from the simulation results can resemble experimental data of up to $95 \%$, so GT-POWER software was very suitable for the development of automotive industry in the future.

The authors would like to acknowledge for the University Malaysia Pahang (UMP) financial support through short-term research grant scheme (RDU172204, RDU130131 and UMP Grant RDU 180335).

\section{References}


1. Motamedifar, N. and A. Shirneshan. Fuel, 221(2018)

2. H Liu, X Ma, B Li, L Chen, Z Wang, J Wang. Fuel, 209 (2017).

3. HG How, HH Masjuki, MA Kalam, YH Teoh, HG Chuah. Fuel, 227 (2018).

4. MHM Yasin, R Mamat, AF Yusop, AA Abdulla, M F Othman, Yusrizal S.T, Iqbal S.T. Energy Proc, 142 (2017).

5. I Örs, S Sarıkoç, AE Atabani, S Ünalan, SO Akansu. Fuel,.234 (2018).

6. S Dharma, HC Ong, HH Masjuki, AH Sebayang, A.S.Silitonga. Energ Conver Manage,.128 (2016).

7. Z Zhang, E Jiaqiang, Y Deng, MH Pham, W Zuo, QingguoPeng, ZibinYin . Energ Convers Manage, 159 (2018).

8. B Li, Y Li, H Liu, F Liu, Z Wang, J Wang. Appl Energy,.206 (2017).

9. MA Asokan, S Kamesh, W Khan. Energy, 145 (2018).

10. AI El-Seesy, H Hassan, S Ookawara. Energy, 147 (2018).

11. MA Ghadikolaei, CS Cheung, KF Yung. Energy, 157 (2018).

12. AS Silitonga, HH Masjuki, HC Ong, AH Sebayang, S.Dharma, F.Kusumo, J.Siswantoro, Jassinnee Milano, KhairilDaud, T.M.I.Mahlia, Wei-HsinChen, BambangSugiyanto. Energy, 159 (2018).

13. M Das, M Sarkar, A Datta, AK Santra. Renew. Energy, 119 (2018).

14. SS Hoseini, G Najafi, B Ghobadian, R Mamat, M.T.Ebadi, TalalYusaf. Renew. Energy, 125 (2018).

15. RS Kumar, K Sureshkumar, R Velraj. Appl. T. Eng, 139 (2018).

16. SS Hoseini, G Najafi, B Ghobadian, R Mamat, Nor Azwadi CheSidik, W.H.Azmi. Renew. S. E. R, 73 (2017)..

17. R Alloune, M Balistrou, S Awad, K Loubar, M.Tazerout. Journal Egy. Ins, 91(2018).

18. R Sathiyamoorthi, G Sankaranarayanan. Renew. Energy, 101(2017).

19. Y Li, M Jia, Y Chang, M Xie, RD Reitz. Energy, 99 (2016).

20. Q Wu, X Xie, Y Wang, T Roskilly. Applied. Energy, 221(2018).

21. MM Musthafa, TA Kumar, T Mohanraj, R Chandramouli. Fuel, 225 (2018).

22. T Mukherjee. rave.ohiolink.edu (2014).

23. R Rahim, R Mamat, MY Taib. Proceedings (1st NCMER),.(2010).

24. Erdiwansyah, R. Mamat, M.S.M. Sani, A. M. Norkhizan, L. Mulyadi. JBETE, 4 (2018)..

25. G Najafi. Fuel, 212 (2017).

26. HG How, HH Masjuki, MA Kalam, YH Teoh. Fuel, 213 (2018.).

27. A Keskin, A Yaşar, Ş Yıldızhan, E Uludamar, FM Emen, Nevzat Külcü. Fuel, 216 (2018).

28. E Ileri. Energy Conversion and Management, 118 (2016).

29. JS Basha. Journal of the Energy Institute, 91 (2018).

30. D Babu, R Anand. Energy, 133 (2017).

31. MHM Yasina, R Mamat. Energy Proc, 110 (2017).

32. TA Kumar, R Chandramouli, T Mohanraj. Ecotox. and Env. Safety, 121 (2015). 